\title{
Influência da biologia no aprendizado do aluno do ensino médio
}

Há uma grande necessidade de melhorar a qualidade de ensino básico no Brasil, e em particular o de ciências. O ensino da biologia pode estimular o raciocínio logico e a curiosidade, ajudar a formar cidadãos mais aptos a enfrentar os desafios da sociedade contemporânea e a fortalecer a democracia assim promovendo a população a gerar melhores condições para participar de debates que são cada vez mais sofisticados sobre temas científicos que afetam nosso cotidiano. A expansão da biologia vem trazendo grandes mudanças, e isso pode acarretar outra compreensão do mundo cientifico, pois contempla a estreita relação da ciência com a tecnologia e a sociedade. Esses aspectos não podem ser eliminados de um ensino que visa formar cidadãos mais atuantes e críticos. Devido a isso, há uma importância de relatar sobre este tema que é de extrema relevância para o aprendizado do aluno. Este trabalho tem o objetivo de realizar uma vasta revisão de literatura para enfatizar a importância da didática para o ensino da biologia, levando em consideração a melhor forma de ministração das aulas da matéria para entendimento dos alunos. Observamos nesta pesquisa que há um desinteresse por parte dos alunos em aprender a biologia. Geralmente, esse fato pode ser ocasionado devido à má ministração das aulas dos professores da matéria, sabendo que a biologia influência de forma significativa o aprendizado dos alunos. Nota-se que é o ensino da disciplina possui grande influência quando são ministradas aulas práticas, e é crucial que o professor relacione o conteúdo a ser dado com o dia a dia do aluno, o que irá motiva-lo a aprender sobre o material proposto.

Palavras-chave: Influência da biologia; Desmotivação do aluno do ensino médio; Metodologia dos professores de biologia; História da Biologia.

\section{Influence of biology in the learning of the student of middle school}

\begin{abstract}
There is a great need to improve the quality of basic education in Brazil, and in particular the sciences. Biology teaching can stimulate logical reasoning and curiosity, help educate citizens better able to meet the challenges of contemporary society, and strengthen democracy, thereby encouraging the population to create better conditions to participate in debates that are increasingly sophisticated on scientific topics that affect our daily lives. The expansion of biology has brought about great changes, and this can lead to another understanding of the scientific world, as it contemplates the close relationship between science and technology and society. These aspects can not be eliminated from a teaching aimed at forming more active and critical citizens. Because of this, there is an importance to report on this topic that is extremely relevant to student learning. This work has the objective of carrying out a vast literature review to emphasize the importance of didactics to the teaching of biology, taking into account the best way of teaching the subject classes for students' understanding. We observed in this research that there is a lack of interest on the part of students in learning biology. Generally, this fact can be due to the poor administration of the teachers 'classes, knowing that biology significantly influences students' learning. It is noted that the teaching of the discipline has great influence when practical classes are taught, and it is crucial that the teacher relates the content to be given with the student's daily life, which will motivate him to learn about the proposed material.
\end{abstract}

Keywords: Influence of biology; Demotivation of the high school student; Methodology of biology teachers; History of Biology.

Topic: Avaliação da Aprendizagem

Reviewed anonymously in the process of blind peer.

Mayara Rodrigues Vieira

Faculdade Guaraí, Brasil

mayaravieira1778@gmail.com

Kayque Souza Oliveira

Faculdade Guaraí, Brasil

http://lattes.cnpq.br/2795059396214565

kayquesouzaoliveira@hotmail.com

Ricardo Henrique Pereira dos Santos

Faculdade Guaraí, Brasil

http://lattes.cnpq.br/2158969775702024

jessicacristinagomes2013@hotmail.com
Received: 19/12/2017

Approved: 28/12/2017
Maraína Pereira Dias

Faculdade Guaraí, Brasil

http://lattes.cnpq.br/6447173238092945

marainadias26@gmail.com

Ana Paula Martins Guimarães

Faculdade Guaraí, Brasil

http://lattes.cnpq.br/5309168123830683

biologa.apmg@gmail.com
Referencing this:

VIEIRA, M. R.; OLIVEIRA, K. S.; SANTOS, R. H. P.; DIAS, M. P.; GUIMARÃES, A. P. M.. Influência da biologia no aprendizado do aluno do ensino médio. Educationis, v.5, n.2, p.41-47, 2017. DOI: http://doi.org/10.6008/SPC2318-3047.2017.002.0005 


\section{INTRODUÇÃO}

Segundo Carvalho et al. (2011) ao fim do século XIX, Ernst Masch apontou com precisão uma dificuldade a respeito do ensino de ciências, declarando que "como pode a mente florescer quando os assuntos são empilhados uns sobre os outros, e novos assuntos empilhados sobre assuntos velhos, mal digeridos" (MACH, 1895). Muito tempo se passou desde que Mach apontou estes problemas, e mesmo assim basta questionar a qualquer educador científico ou pesquisador da área do ensino de biologia para percebermos que a grande dificuldade do excesso de conteúdos permanece. Um grande problema enfrentado no ensino de biologia é a forma fragmentada como o conhecimento biológico é abordado nos livros didáticos, principalmente em sala de aula.

Há uma grande necessidade de melhorar a qualidade de ensino básico no Brasil, e em particular o de ciências. O ensino da biologia pode estimular o raciocínio logico e a curiosidade, ajudar a formar cidadãos mais aptos a enfrentar os desafios da sociedade contemporânea e a fortalecer a democracia, assim promovendo a população em gerar melhores condições para participar de debates que são cada vez mais sofisticados sobre temas científicos que afetam nosso cotidiano (SANTOS et al., 2011). O mundo científico tecnológico em que vivemos necessita do cidadão com conhecimentos apurados na área de biologia, que tem o intuito de oportunizar o enfrentamento dessa exigência. As aulas de biologia são desafiadoras, pelo motivo de encontrar algo que desperte interesse dos alunos, torna-se uma tarefa difícil e preocupante (BEZERRA et al., 2017).

É necessário que o professor saiba incentivar os seus alunos para que haja aulas de diálogo mais aberto, onde os professores e alunos se respeitem, e saibam perceber um ao outro como agentes de mudanças, podendo assim trazer melhorias para o docente e ambiente escolar (SILVA, 2010). Portanto, é de suma importância que os alunos estejam estimulados para esse campo do saber, pois os domínios do conhecimento científico é um degrau para o desenvolvimento de um país (SANTOS et al., 2011).

Santos (2011) relata que a expansão da biologia vem trazendo grandes mudanças, e isso pode acarretar outra compreensão do mundo cientifico, pois contempla a estreita relação da ciência com a tecnologia e a sociedade. Esses aspectos não podem ser eliminados de um ensino que visa formar cidadãos mais atuantes e críticos. Devido a isso, dá-se a importância de relatar sobre este tema que é de extrema relevância para o aprendizado do aluno. Este trabalho tem o objetivo de realizar uma vasta revisão de literatura para enfatizar a importância da didática para o ensino da biologia, levando em consideração a melhor forma de ministração das aulas da matéria para entendimento dos alunos.

\section{METODOLOGIA}

O estudo foi realizado através de um levantamento bibliográfico por meio de uma revisão de literatura, considerando a relevância do tema. Esta pesquisa foi realizada nos períodos de outubro a novembro de 2017, com os seguintes bancos de dados: LILACS, SciELO, Google Acadêmico e Arquivos de dissertações, selecionando trabalhos em português para o desenvolvimento do tema abordado. Para a 
pesquisa virtual, fez-se uso e combinação dos seguintes descritores: Influência da biologia; Desmotivação do aluno do ensino médio; Metodologia dos professores de biologia e História da Biologia. Dos 24 artigos selecionados, foram extraídas informações em relação ao ensino da biologia no ensino médio, da influência que a biologia causa na vida e no aprendizado do aluno, e quais sãos os fatores que causam a desmotivação dos alunos em aprender a biologia.

\section{Surgimento do Ensino da Biologia}

Por volta de 1950, as políticas científicas e tecnológicas passaram por um processo de institucionalização, tendo como intuito o crescimento e o progresso do país (NASCIMENTO et al., 2010). Com o passar dos anos, houve várias mudanças, mas foi a partir dos anos 1990 que se tornou explícita a necessidade de analisar a articulação existente entre a ciência, tecnologia e sociedade, ocasionando o surgimento de um panorama complexo de dúvidas a respeito da produção científica e tecnológica, mas colocando sempre evidente a falta de relação dessa produção com as necessidades da maioria da população brasileira (NASCIMENTO et al., 2010).

Borba (2013) relata que a escola deu inicio a seus esforços com intuito de ofertar um modelo de ensino de ciência natural com o foco de contemplar os objetivos supracitados. Essa fundamentação teórica envolvia os conteúdos básicos para ministrar uma instrução de Ciências da Natureza, que por sua vez contemplava os conhecimentos de Física e Biologia em uma mesma matéria dada em aulas expositivas, que tinha o foco de envolver o máximo de teorias, conceitos e informações que pudessem para ensinar aos alunos (BORBA, 2013). Essa concepção de ciência teve uma repercussão dos seus modelos escolares, e fez com que a ação docente tivesse um perfil relacionado ao campo da ciência ainda experimental no século XVIII, com o objetivo de a escola ter que envolver em seu planejamento uma determinada noção de ciência enquanto método de análise (PORTO et al., 2010).

\section{Causas do desinteresse no processo de ensino aprendizagem da disciplina de Biologia}

De acordo com Palomares (2017), atualmente os problemas relacionados à educação vêm sendo cada vez mais discutidos. Este fato é devido ao Brasil atualmente, viver uma crise na rede básica da educação. As desigualdades econômicas e sociais, a crise de valores e o conflito de gerações, a falta de condições de trabalho dos professores e outros fatores, podem influenciar diretamente, fazendo com que os professores não se sintam capazes de atender às necessidades específicas de cada aluno (PALOMARES, 2017).

Muitos alunos apresentam dificuldade em estudar e aprender conceitos de Ciências e Biologia, e isso pode estar relacionado ao fato de a educação científica estar sendo repassada de forma incorreta pelos professores, causando esta deficiência no ensino (PERETTI et al., 2015). O ensino da biologia básica deveria estar voltado a repassar conceitos básicos aos alunos, com o objetivo de formar cidadãos, e não somente voltada à preparação de futuros cientistas. 
Portanto, quando os alunos não têm motivação ou interesse pela matéria estudada, ocorrerá a indisciplina dos mesmos. É importante que os alunos estejam motivados e interessados para que assim consigam uma preparação básica para a cidadania e continuem aprendendo para que seja capaz de se adaptar com flexibilidade as novas condições de ocupação ou aperfeiçoamento posteriores, isso irá ajudar para que o aluno em sua ética e o seu desenvolvimento de autonomia intelectual (VIEIRA, 2010).

\section{Influência da biologia na vida e aprendizagem do aluno}

Segundo Lemos et al. (2011), a aprendizagem pode implicar em atribuir o conceito pessoal para ideias que são percebidas, processadas e representadas mentalmente, tendo um caráter idiossincrático, que pode determinar o modo como à pessoa se relaciona com o meio, o modo de sentir, de pensar e de agir. O que, por sua vez, quanto mais estável e organizada for a estrutura cognitiva da pessoa, maior será a possibilidade de perceber novas informações, realizar novas aprendizagens e de agir com autonomia da sua realidade.

Grimes et al. (2013) relatam que o processo de construção conceitual do aluno é fundamental para que o mesmo progrida a partir das suas concepções, o que requer um aprofundamento nos diversos modelos e teorias necessários para a interpretação da sua realidade, sem esquecer-se do compromisso da ciência com a sociedade. A partir disso é correto dizer que o ensino da biologia pode estimular os alunos a serem críticos e terem a plena capacidade de refletir sobre assuntos estudados, melhorando seu aprendizado. É necessário que o professor faça uso de diferentes estratégias para o desempenho do processo de ensino e aprendizagem, interligando aos conteúdos em sala de aula, as vivências dos alunos com o uso de tecnologias (ROCHA, 2016). Para que o aluno seja influenciado, ele também necessita desempenhar de forma positiva seu papel de aprendizado e na construção do seu saber, desenvolvendo seu estudo e levantando hipóteses, de uma forma elementar e subjetiva em relação ao seu estudo (PUCINELLI, 2010).

O ensino da biologia no ensino médio tem o intuito de possibilitar que o aluno entenda a natureza como algo dinâmico e que assim possa compreender o seu real papel social com o meio ambiente, com compromissos e responsabilidades (SCHELEY et al., 2014). Viecheneski et al. (2013) afirmam que o ensino da biologia tem um papel de despertar nos estudantes o interesse pelas carreiras científicas, ampliando a possibilidade de o país contar com profissionais capazes de produzir conhecimentos científicos e tecnológicos, que poderá contribuir para o desenvolvimento econômico e social da nação (VIECHANESKI et al., 2013). É correto promover o ensino da biologia com qualidade nas escolas, assegurando o futuro do país. O conhecimento é a peça-chave para alcançar resultados positivos e abrir possibilidades bem-sucedidas de inserção no mundo globalizado e competitivo.

\section{Desenvolvimento de aulas dos professores de biologia}

Segundo Teodoro et al. (2016), são de responsabilidade do professor de Biologia ensinar os conceitos biológicos que comporão a base científica para que os alunos compreendam o mundo e possam atuar nele de forma mais crítica, assim podendo decidir em beneficio individual e coletivo, levando em conta o papel 
do homem no mundo. O educador deve estar preparado, e ter uma formação inicial, repassando com qualidade e com eficiência o conteúdo pedagógico, podendo mostrar aos seus alunos que o conhecimento é construído e que eles fazem parte desta construção, e com isso preparar-se para enfrentar, resolver problemas e analisar as consequências sociais da ciência e da tecnologia na sociedade moderna.

De acordo com Pimentel et al. (2017) percebe-se que o modo como o professor ensina biologia e as suas concepções sobre os conhecimentos científicos poderá influenciar as ideais, atitudes e as motivações dos alunos em relação a aprender a biologia. Seixas et al. (2017) relata que é preciso que o professor se qualifique à medida em que atua no processo de mediação de conhecimentos aos seus alunos. É importante fazer o uso de diversos materiais para que o professor aprimore o domínio do conteúdo e o aprendizado do educando, e assim exerça a alfabetização com qualidade. Mas é necessário perceber que as aulas práticas não possuem em si todos os conteúdos que se quer ensinar (SEIXAS et al., 2017). Ou seja, estas aulas precisam fazer parte de uma sequência de didática que tenha o envolvimento de exposições teóricas, registros dos alunos e confrontações de ideias, que possam levar a construção de conceitos pelos alunos.

É preciso que para o ensino de biologia no ensino médio, o professor tenha atenção para repassar o que the é proposto, pois este ensino possui um papel de grande importância, o mesmo tem que preparar seus alunos para terem sempre consciência crítica e cultural, e relevando as individualidades regionais e limitações reais do ambiente escolar (MORAES et al., 2017).

\section{CONCLUSÕES}

Observamos nesta pesquisa que há um desinteresse por parte dos alunos em aprender biologia. Geralmente, esse fato pode ser ocasionado devido a uma ruim ministração das aulas dos professores da matéria, pois sabem que a biologia influencia de forma significativa o aprendizado dos alunos. Nota-se que é o ensino da mesma possui grande influência quando são ministradas aulas práticas, e o professor relacione o conteúdo a ser dado com o dia a dia do aluno, o que irá motiva-lo a aprender sobre o material proposto. (BUENO et al., 2012).

Concluímos que o ensino da biologia tem varias funções, como a de contribuir para que o indivíduo seja capaz de compreender e aprofundar em explicações atualizadas de processos e de conceitos biológicos. (MALAFAIA et al., 2010). Assim, entende-se que as metodologias utilizadas nas aulas de biologia devem ser inclusas formas educativas que possa despertar a atenção e motivação de interesse dos alunos. Portanto, é viável que seja utilizado modelos didáticos e aulas práticas para promover a investigação dos alunos do material proposto, e os mesmos possam formular ideias com relação ao que está sendo trabalhado e tirando dúvidas diretamente com o educador e os colegas de classe (LARENTIS et al., 2010).

É de grande relevância a utilização de aulas práticas, o que auxilia bastante para o melhor entendimento da matéria repassada, como também a utilização de multimídia que é uma importante ferramenta pra a promover o interesse e motivação dos alunos para aprender o conteúdo e atitudes positivas, como o cuidado ao meio ambiente (VASCONCELOS et al, 2010). Acreditamos que com a 
implementação das aulas práticas na ministração da biologia em sala de aula, possa contribuir para que diminua o desinteresse dos alunos para com a matéria, promovendo o interesse pela influência que a biologia pode causar no aprendizado do aluno. Contribuindo para a construção de uma alfabetização científica de qualidade e uma educação mais comprometida.

\section{REFERÊNCIAS}

BARBÁRA, V. F.; MALAFAIA, G.; RODRIGUES, A. S. L.. Análise das concepções e opiniões de discentes sobre o ensino da biologia. Revista Eletrônica de Educação, Goiânia, 2010.

BEZERRA, D. S.; MARQUES, J. A.; SOARES, A. M.. Concepções acerca da biologia entre discentes do ensino médio no município de Cajazeiras - Paraíba. Revista de Pesquisa Interdisciplinar, Cajazeiras, n.2, 2017.

BORBA, J. B.. Uma breve retrospectiva no ensino de biologia no Brasil. Medianeira: 2013;

BUENO, G. G. B.; FARIAS, S. A.; FERREIRA, L. A.. Concepções de ensino de ciências no inicio do século XX: o olhar do educador alemão Georg Kerschensteiner. Revista Ciências e Educação, São Paulo, v.18, n.2, 2012.

CALABRO, L.; SEIXAS, R. H. M.; SOUSA, D. O.. A formação de professores e os desafios de ensinar ciências. Revista Thema, Porto Alegre, v.14, n.1, 2017.

CAMPOS, L. M. L.; SHELEY, T. R.; SILVA, C. R. P.. A motivação para aprender biologia: o que revelam alunos do ensino médio. Revista SBEnBio, São Paulo, n.7, 2014.

CAMPOS, L. M. L.; TEODORO, N. C.. O professor de biologia e dificuldades com os conteúdos de ensino. Revista da SBEnBio, São Paulo, n.9, 2016.

CARLETTO, M.; VIECHENESKI, J. P.. Por que e para quê ensinar ciências para crianças. Revista Brasileira de Ensino de C\&T, Paraná, v.6, n.2, 2013.

CARVALHO, I. N.; EL-HANI, C. N.; NETO, N. F. N.. Como selecionar conteúdos de biologia para o ensino médio?. Revista de educação, ciências, matemática, Salvador, v.1, n.1, 2011

CECCATTO, V. M.; COSTA, C. H. C.; SANTANA, J. R.; VASCONCELOS, A. L. S.. Importância da abordagem prática no ensino de biologia para a formação de professores (licenciatura pela em ciências/ habilitação em biologia/química- EUCE) em Limoeiro do Norte - CE. Ceará, 2010.

FALCÃO, E. B. M.; OLIVEIRA, M. V. P.; PIMENTEL, P. M. S.. Teoria e prática no âmbito do ensino médio: analise de casos no Piauí e Ceará para o ensino de biologia. Revista RenCiMa, Teresina, v.8, n.3, 2017.

FALCÃO, E. B. M.; PORTO, P. R. A.. Teorias da origem e evolução da vida: dilemas e desafios no ensino médio. Revista Ensaio, Salvador, v.12, n.3, 2010.
FERNANDES, H. L.; MENDONÇA, V. M.; NASCIMENTO, F.. O ensino de ciências no Brasil: História, formação de professores e desafios atuais. Revista Histedbr, Campinas, n. 39, 2010

GRIMES, C.; SCHROEDER, E.. A origem da vida, sobre a ótica de licenciados de um curso de ciências biológicas. Revista Electronica de Ensenanza de IOS Ciências, Florianópolis, v.12, n.1, 2013

HENRIQUE, A. L. S.; MORAIS, K. K. C.. Formação de professores de biologia para o ensino médio integrado. Natal, 2017.

LARENTIS, C.; MALACARCE, T.J.; SEREIA, D. A.. A importância dos modelos didáticos no ensino de ciências nas series do ensino fundamental. São Paulo: 2010.

LEMOS, E. S.; MOREIRA, M. A.. A avaliação da aprendizagem significativa em biologia: um exemplo com a disciplina em biologia. Revista Meamingful Learning Review, Porto Alegre, v.1, n.2, 2011.

PALOMARES, D. O. A.. Educação: como a relação alunoprofessor influencia na deficiência do aprendizado. Londrina, 2014.

PERETTO, E.. Influência do PIBID nas aulas de ciências e biologia. Revista Unoesc \& Ciências, v.6, n.2, Lodrina, 2015.

PUCINELLI, R. H.. Aprendizado dos conceitos de flor e fruto e sua utilização pelos alunos de ciências biológicas do I. BUSP. São Paulo: 2010.

ROCHA, L. B.. A importância das práticas de ciências para o processo ensino aprendizagem. Revista Científica Intelletto, Vitória, v.2, n.2, 2016.

SANTOS, A. C.. A importância do ensino de ciências da percepção de alunos de escolas da rede pública municipal de Criciúma - SC. Revista Univap, São Paulo, v.17, n.30, 2011.

SILVA, B. V. C. S.. A natureza da ciência pelos alunos do ensino médio: um estudo exploratório. Latin-American Journal of Physics Education, Teresina, v.4, n.3, 2010.

VIEIRA, F. L.. Causas do desinteresse e desmotivação dos alunos nas aulas de biologia. Revista Universitas Humanas, Brasília, v.7, 2010. 